\title{
On the determinants of giving under risk
}

\author{
Jana Freundt*, Andreas Lange \\ Department of Economics, University of Hamburg, Von Melle Park 5, 20146 Hamburg, Germany
}

\section{A R T I C L E I N F O}

\section{Article history:}

Received 22 September 2016

Received in revised form 10 July 2017

Accepted 14 July 2017

Available online 21 July 2017

\section{JEL classification:}

C91

D03

D63

D64

D81

\section{Keywords:}

Risk preferences

Prosocial behavior

Procedural fairness

Empathy

\begin{abstract}
A B S T R A C T
By means of a laboratory experiment we investigate the role of risk preferences for prosocial behavior. Modifying the way the decision-maker or the recipient are exposed to risk, our design allows to identify how risk preferences impact giving-decisions. By measuring the decision-makers' risk preferences regarding both their own as well as the recipients' payoff, we generate new insights into how social preference theories may extend to risky situations.
\end{abstract}

(c) 2017 Elsevier B.V. All rights reserved.

\section{Introduction}

The role of risk and uncertainty for pro-social behavior has received substantial interest in the recent literature. Motivating examples range from charitable giving with uncertain impacts, climate policies demanding current generations to bear abatement costs to increase the chance of limiting future climate impacts, to every day interactions like educating and raising children to impact their future well-being. Within the behavioral economic literature, a particular focus has been set on discussing the role of comparisons of payoff chances versus comparisons of final payoffs when ex ante evaluating the fairness of allocations in the presence of risk. ${ }^{1}$

As opposed to a comparison of ex post payoffs, ex ante procedural fairness denotes equality of chances to win a given prize, irrespective of who finally receives that prize ex post. When extending social preferences to risky situations, the procedural fairness of an allocation is typically evaluated by a comparison of expected values of lotteries (Fudenberg and Levine, 2012; Brock et al., 2013; Saito, 2013). While the implicit assumption of risk-neutrality simplifies the exposition of these models, it also leaves open different ways of extending these models to capture risk aversion. Risk aversion may, in fact, crucially impact pro-social behavior. This argument has been picked up in a comment by Krawczyk and LeLec (2016) and the subsequent reply by Brock et al. (2016). Krawczyk and LeLec (2016) suggest that giving to others may decline under

\footnotetext{
* Corresponding author.

E-mail addresses: Jana.Freundt@wiso.uni-hamburg.de (J. Freundt), Andreas.Lange@wiso.uni-hamburg.de (A. Lange).

1 Experimental evidence suggests that both fairness views are important to understand giving decisions under risk, see for example Bolton et al. (2005), Krawczyk and LeLec (2010), Rohde and Rohde (2011), Brock et al. (2013).
} 
Table 1

Experimental design: lottery choices in Part 1.

\begin{tabular}{|c|c|c|c|c|}
\hline & \multicolumn{2}{|c|}{ Outcomes } & \multirow[b]{2}{*}{ EV } & \multirow[b]{2}{*}{ Std.dev. } \\
\hline & A & B & & \\
\hline 1 & 52 & 52 & 52 & 0 \\
\hline 2 & 44 & 68 & 56 & 12 \\
\hline 3 & 36 & 84 & 60 & 24 \\
\hline 4 & 28 & 100 & 64 & 36 \\
\hline 5 & 20 & 116 & 68 & 48 \\
\hline 6 & 0 & 136 & 68 & 68 \\
\hline
\end{tabular}

risk aversion: intuitively, the reward of giving decreases because the certainty equivalent of a risk-averse recipient is smaller under risk. In contrast, Brock et al. (2016) point out that this smaller certainty equivalent may lead to larger giving if the decision-maker is concerned with inequality in the sense of Fehr and Schmidt (1999). Thus, the direction of the impact of risk aversion on giving crucially depends on how an individual's social preference interacts with risk aversion. The existent literature is inconclusive on this question and it ultimately remains an empirical question how risk aversion affects prosocial behavior.

In this paper, we provide experimental evidence from variants of dictator games to clarify the role of risk and risk aversion for prosocial preferences. Importantly, we generate separate measures of a decision maker's risk aversion over own payoff and another person's payoff as well as the other person's own risk preference. A related literature has already shown that decisions may differ when making choices over lotteries for oneself vs. on behalf of an agent. ${ }^{2}$ Having separate measures of risk aversion allows us to identify to what extent either risk attitude matters when distributing payoff chances in variants of the dictator game. In addition, we examine the role of social information.

We show that both measures of risk attitudes are informative of prosocial behavior under risk. While risk-averse dictators reduce giving when their own payoff becomes risky, a more nuanced picture evolves when the payoff of the recipient becomes risky. We do not find evidence that believed or actual risk aversion of the recipient leads the dictator to give less. On the contrary, giving particularly declines when dictators know or believe the recipient to be non-risk-averse. We identify strong heterogeneities in individual reactions to risk in giving situations. By showing the importance of differentiating between risk types instead of concentrating on average treatment effects measures of aggregate behavior, our findings indicate a more complex way how prosocial preferences extend to situations under risk.

\section{Experimental design}

The experiment consists of two parts: Part 1 elicits subjects' risk preferences, while Part 2 confronts subjects with five variants of the dictator game.

In Part 1, we use the simple risk elicitation task by Dave et al. (2010) and Eckel and Grossman (2008) to generate separate measures of risk attitudes regarding the payoff of the decision maker himself as well as the payoff of another player. For this, subjects make two decisions in random order: one on a lottery that determines their own payoff, and another decision on a lottery that determines the payoff of another subject. For both decisions, subjects chose one out of six 50/50-lotteries as presented in the first two columns of Table 1. Lotteries are constructed such that a higher expected value corresponds to a larger variance (see third and fourth column of Table 1 ). We refer to the lottery choices as $L_{\text {own }}$ for choices over own payoffs and as $L_{\text {other }}$ for choices over the other one's payoffs. Individuals are expected to choose lottery 5 or 6 if they are risk-neutral with respect to their own or the other subject's payoff ( $L_{o w n}>4$ or $L_{\text {other }}>4$, respectively), respectively. Riskseeking individuals may choose lottery 6 and risk-averse individuals may choose lotteries 1 to $4 .{ }^{3}$ Correspondingly, we code subjects who choose 1 through 4 as RAown and those with choices 5 or 6 as NRAown (for non-risk-averse) when the lottery determines their own payoff. Those who made risk-averse (non-risk-averse) choices for their randomly matched player are defined as RAother (NRAother). In addition, we ask participants to state their belief about the mode choice for own payoff (referred to as $L_{\text {belief }}$ ) (as in Chakravarty et al. (2011)). This task is conducted after all choices have been made and is incentivized with 50 cents for a correct guess.

Part 2 consists of five dictator games, played in random order, summarized in Table 2. Participants stay in the pairs from Part 1. Before decisions are taken, a random draw determines who is assigned the role of proposer and receiver. Players are told that all giving decisions are revealed to the receivers at the end of the experiment in order to close the 'moral wiggleroom' (Dana et al., 2007) and that one decision will be randomly selected for payment. Before beginning with part 2, dictators see a summary of their own lottery choices. In a between treatment design, we explore the role of social information: half of the dictators additionally receive information of the (own) lottery choice of the receiver.

\footnotetext{
${ }^{2}$ Chakravarty et al. (2011) and Faro and Rottenstreich (2006) find more risk neutrality in choices on behalf of an agent, while Pahlke et al. (2015), Agranov et al. (2014) or Eckel and Grossman (2008) find the opposite.

${ }^{3}$ With this interpretation of individuals' choices we follow, among others, Dave et al. (2010). Note, however, that subjects with a very low degree of risk aversion might also choose lottery 5.
} 
Table 2

Experimental design: payoffs structure for treatments in Part 2.

\begin{tabular}{lll}
\hline Game & Payoff to proposer & Payoff to receiver \\
\hline NR & $100-x$ & $x$ \\
OR & $100-x$ & 100 with $p=\frac{x}{100}$ \\
& 100 with $p=\frac{100-x}{100}$ & 0 with $p=\frac{100-x}{100}$ \\
SR & 0 with $p=\frac{x}{100}$ & $x$ \\
NOR & $100-x_{1}-x_{2}$ & $x_{1}+\left(100-x_{1}\right)$ with $p=\frac{x_{2}}{100-x_{1}}$ \\
& & $x_{1}$ with $p=\frac{\left(100-x_{1}\right)-x_{2}}{100-x_{1}}$ \\
NSR & $100-x_{1}$ with $p=\frac{\left(100-x_{1}\right)-x_{2}}{100-x_{1}}$ & $x_{1}+x_{2}$
\end{tabular}

In all tasks in Part 2, the proposer's endowment equals 100 units of the experimental currency unit 'Taler', while the receiver has no endowment. The payoff structure of the tasks is summarized in Table 2. Task NoRisk (NR) is a standard dictator game, in which the dictator receives $100-x$ tokens when giving $x$ tokens to the recipient. In task OtherRisk (OR), the recipient faces a gamble between winning 100 or 0 tokens with a probability of winning given by $x / 100$, while the dictator receives $100-x$ tokens for sure. Task SelfRisk(SR) mirrors OR as it gives a certain payoff $x$ to the recipient, while the dictator receives 100 or 0 , with the chance of winning being $(100-x) / 100$. While all treatments coincide in expected value of giving, OR and SR introduce riskiness into the giving decision with the risk born either by the recipient (OR) or the dictator (SR). As robustness checks, we add two complementary tasks which allow for both risky and non-risky giving, i.e. where the proposer can choose her preferred giving channel. Task NOR combines NR and OR with the dictator receiving $100-x_{1}-x_{2}$, while the recipient receives at least $x_{1}$, but may get 100 tokens with probability $x_{2} /\left(100-x_{1}\right) \cdot{ }^{4}$ Analogously, task NSR combines game NR and SR by giving the recipient a payoff of $x_{1}+x_{2}$ while the dictator gives up $x_{1}$ for sure, but may lose all payoff with probability $x_{2} /\left(100-x_{1}\right)$. That is, for a choice of $x_{2}=0$ both NOR and NSR coincide with NR, while for $x_{1}=0$ the payoff structures are identical to OR and SR, respectively. A decision-maker thus has a wider range of giving options, consisting of giving safe tokens vs. giving chances to win in NOR, and giving which decreases own payoff for sure vs. giving which makes own payoff risky in NSR. As such, the type of risk preferences may not only determine how much a player gives, but also the channel that is primarily being used.

We employ a within-subject design where participants stay with the same randomly matched partner for the whole experiment. After the participants complete the experiment, feedback is given about the outcomes of the lotteries and the decisions of the proposer. One task is randomly chosen for payment. ${ }^{5}$

While we are primarily interested in the decisions of the proposers, we additionally ask receivers to state their expectations about the amount given to them in each game and, after all choices have been made, to judge the fairness of the allocation their dictator chose for them (on a scale: 1 (very fair) through 5 (unfair)).

The experiment has been conducted at the Experimental Laboratory of the School for Business, Economics and Social Sciences at the University of Hamburg in 2013 and 2015. It was programmed in z-tree (Fischbacher, 2007). 282 students of the University of Hamburg participated in 10 sessions of approximately 45 minutes. The average payoff was $10.14 €$, instructions can be found in a downloadable supplement to the paper.

\section{Predictions}

The treatments are designed to investigate the role that risk aversion plays within prosocial preferences. All treatments allow for identical allocations of expected payoffs such that ex ante fairness preferences based on comparisons of expected values (Brock et al., 2013) predict the same total giving in all treatments. In other words, for risk-neutral players we should observe no treatment differences.

\footnotetext{
4 This payoff structure was constructed to (i) correspond to giving $x_{1}+x_{2}$ tokens in expectation, and (ii) for the receiver to have a safe minimum payoff of $x_{1}$, while we wanted to keep the maximum payoff at 100 . Thus, the probability of getting 100 necessarily is given by $x_{1}+x_{2}=p 100+(1-p) x_{1}$, thus implying $p=x_{2} /\left(100-x_{1}\right)$.

5 The choice of a within subjects design is not completely innocent given our interest in risk aversion for prosocial behavior. Subjects may play a metagame and - for example - increase giving in one treatment and reduce it in another treatment without affecting the expected payoff to themselves or another player across all games. The same issue would, however, result if all periods are paid. The only workaround would be to have one-shot decisions. We decided to follow the design by Brock et al. (2013) to allow for within subjects comparisons. Giving additional feedback to the receiver on the choices in all treatments can be expected to not only close the moral wiggle room, but also to reduce the likelihood that subjects view the full game as a meta-game. Moreover, the order of the treatments is randomized. If a meta-game is played, we would therefore expect order effects to be present when considering the individual data. We do not find any indication that such order effects exist.
} 
Table 3

Summary of choices for lotteries in Part $1 . L_{o w n}, L_{\text {other }}$ refer to the choices of the lotteries in Table 1 when making the choice over own payoff or over the other one's payoff, respectively. $L_{\text {belief }}$ states the subjects' beliefs about the mode in $L_{\text {own }}$.

\begin{tabular}{|c|c|c|c|c|c|c|c|}
\hline & 1 & 2 & 3 & 4 & 5 & 6 & Mean \\
\hline \multicolumn{8}{|c|}{ Proposers } \\
\hline$L_{\text {own }}$ & 41 & 27 & 30 & 13 & 18 & 12 & 2.9 \\
\hline$L_{\text {other }}$ & 35 & 28 & 24 & 9 & 15 & 13 & 2.84 \\
\hline$L_{\text {belief }}$ & 53 & 42 & 30 & 5 & 7 & 4 & 2.19 \\
\hline \multicolumn{8}{|l|}{ All } \\
\hline$L_{o w n}$ & 69 & 55 & 64 & 29 & 35 & 29 & 3.01 \\
\hline$L_{\text {other }}$ & 68 & 55 & 45 & 19 & 35 & 26 & 2.9 \\
\hline$L_{\text {belief }}$ & 101 & 82 & 55 & 17 & 18 & 8 & 2.3 \\
\hline
\end{tabular}

Table 4

Summary of switching behavior between $L_{o w n}$ and $L_{\text {other }}$ in Part 1.

\begin{tabular}{|c|c|c|c|c|c|c|}
\hline & \multicolumn{6}{|c|}{$L_{o w n}$} \\
\hline & 1 & 2 & 3 & 4 & 5 & 6 \\
\hline \multicolumn{7}{|c|}{$L_{\text {other }}$} \\
\hline 1 & 36 & 9 & 2 & - & 4 & 4 \\
\hline 2 & 11 & 22 & 9 & 2 & 3 & 1 \\
\hline 3 & 7 & 21 & 19 & 7 & 5 & 3 \\
\hline 4 & 4 & 1 & 11 & 5 & 2 & 2 \\
\hline 5 & 5 & 1 & 3 & 3 & 17 & 2 \\
\hline 6 & 5 & 1 & 1 & 2 & 3 & 14 \\
\hline
\end{tabular}

Based on a version of the model by Fehr and Schmidt (1999) that incorporates aversion to ex post payoff inequality, ${ }^{6}$ Brock et al. (2013) show that giving in OR will be smaller than in NR. For such preferences, giving in SR can be expected to be even smaller for risk-averse players. ${ }^{7}$

In presence of ex ante comparisons for a situation where the recipient's payoff is risky (OR), Brock et al. $(2013,2016)$ indicate that giving to a risk-averse recipient may increase if the dictator wants to equalize certainty equivalents. Krawczyk and LeLec (2016) point out the reverse effect that giving to a risk-averse recipient may decline because it becomes more costly for the dictator to convert one unit of his wealth into the certainty equivalent of the other player. ${ }^{8}$ As such, ex ante preferences based on comparisons of certainty equivalents may theoretically lead to increases or decreases of giving for riskaverse types. Opposite reasoning applies for risk-loving types. The difference in giving between NR and OR thus remains an empirical question. When the dictator's payoff becomes risky (SR), both the price effect as well as an attempt to equalize certainty equivalents would lead to reduced giving.

We hypothesize that our measure of own risk aversion has particular explanatory power when considering the change from NR to SR. The belief about the risk aversion of the other player, however, is expected to matter in OR when no information is given, while the revealed risk-attitude of the recipient is expected to drive the treatment difference when information is given.

\section{Results}

The two choices over lotteries show on average moderate risk aversion, see Table 3. The lottery choices allow us to categorize 141 proposers as RAown (111) vs. NRAown (30). Out of 124 proposers, ${ }^{9}$ we code 96 players as RAother and 28 as NRAother. ${ }^{10}$ We use these classifications to study the impact on giving decisions in the respective tasks. The results are not significantly altered when using different categorizations.

\footnotetext{
${ }^{6}$ Naturally, alternative ways of specifying ex post preferences could lead to modified results.

7 In fact, OR and SR both lead to exactly the same differences in payoffs with the same probabilities, hence to the same ex post inequality for given $x$ : with probability $x / 100$ the receiver gets $x$ tokens more than the proposer, while with probability $(100-x) / 100$ the proposer gets $100-x$ more than the receiver. As such, inequality aversion with respect to final payoffs has the same impact on giving in OR and SR. However, the riskiness of own payoff in SR should typically lead to lower giving relative to OR for players who are risk-averse with respect to their own payoff.

8 Krawczyk and LeLec (2016) discuss the importance of efficiency orientation. We concentrate on preferences over own and other certainty equivalents, instead of also considering efficiency as we have no measure to distinguish between own or other risk aversion and risk aversion with respect to efficiency.

${ }_{9}$ Due to a coding error, we miss 17 observations for the risk task for the other player's payoff, thus a full characterization is possible for 124 out of 141 subjects.

10 The distribution of risk-attitudes is similar for those who ended up being receivers. In particular, in the information treatment, 58 receivers are RAown and 12 are NRAown which correspond to RApartner and NRApartner by which we code the information about risk attitudes of recipients given to dictators in the information treatment.
} 
Table 5

Summary of giving behavior (mean (std.)) and fraction of subjects with positive giving in Part 2.

\begin{tabular}{|c|c|c|c|c|c|c|}
\hline & $n$ & All & $R A_{\text {own }}$ & $N R A_{\text {own }}$ & $R A_{\text {other }}$ & $N R A_{\text {other }}$ \\
\hline \multirow{4}{*}{ NR } & & 141 & 111 & 30 & 96 & 28 \\
\hline & $x$ & 22.46 & 24.79 & 13.83 & 23.72 & 19.29 \\
\hline & & $(21.32)$ & (21.37) & (19.06) & (20.05) & $(25.92)$ \\
\hline & $x>0$ & $71.6 \%$ & $79.3 \%$ & $43.3 \%$ & $76 \%$ & $53.6 \%$ \\
\hline \multirow[t]{2}{*}{ OR } & $x$ & $\begin{array}{l}19.60 \\
(22.13)\end{array}$ & $\begin{array}{l}21.18 \\
(22.58)\end{array}$ & $\begin{array}{l}13.77 \\
(19.67)\end{array}$ & $\begin{array}{l}20.93 \\
(22.54)\end{array}$ & $\begin{array}{l}13.39 \\
(21.82)\end{array}$ \\
\hline & $x>0$ & $73.8 \%$ & $80.2 \%$ & $50 \%$ & $79.2 \%$ & $50 \%$ \\
\hline \multirow[t]{2}{*}{ SR } & $x$ & $\begin{array}{l}15.11 \\
(22.89)\end{array}$ & $\begin{array}{l}15.15 \\
(20.54)\end{array}$ & $\begin{array}{l}14.93 \\
(30.47)\end{array}$ & $\begin{array}{l}12.85 \\
(18.07)\end{array}$ & $\begin{array}{l}19.79 \\
(32.04)\end{array}$ \\
\hline & $x>0$ & $56 \%$ & $61.3 \%$ & $36.7 \%$ & $58.3 \%$ & $42.9 \%$ \\
\hline \multirow[t]{2}{*}{ NOR } & $x_{1}+x_{2}$ & $\begin{array}{l}24.04 \\
(25.67)\end{array}$ & $\begin{array}{l}25.82 \\
(25.95)\end{array}$ & $\begin{array}{l}17.47 \\
(23.88)\end{array}$ & $\begin{array}{l}24.48 \\
(24.94)\end{array}$ & $\begin{array}{l}20.86 \\
(28.43)\end{array}$ \\
\hline & $x_{1}+x_{2}>0$ & $75.2 \%$ & $81.1 \%$ & $53.3 \%$ & $80.2 \%$ & $53.6 \%$ \\
\hline \multirow[t]{2}{*}{ NOR_sure } & $x_{1}$ & $\begin{array}{l}13.84 \\
(17.72)\end{array}$ & $\begin{array}{l}15.23 \\
(16.86)\end{array}$ & $\begin{array}{l}8.70 \\
(20.07)\end{array}$ & $\begin{array}{l}14.17 \\
(16.22)\end{array}$ & $\begin{array}{l}10.50 \\
(16.58)\end{array}$ \\
\hline & $x_{1}>0$ & $64.5 \%$ & $72.1 \%$ & $36.7 \%$ & $69.8 \%$ & $39.3 \%$ \\
\hline \multirow[t]{2}{*}{ NOR_risky } & $x_{2}$ & $\begin{array}{l}10.20 \\
(15.36)\end{array}$ & $\begin{array}{l}10.59 \\
(15.77)\end{array}$ & $\begin{array}{l}8.77 \\
(13.89)\end{array}$ & $\begin{array}{l}10.31 \\
(15.5)\end{array}$ & $\begin{array}{l}10.36 \\
(17.46)\end{array}$ \\
\hline & $x_{2}>0$ & $56 \%$ & $57.7 \%$ & $50 \%$ & $58.3 \%$ & $46.4 \%$ \\
\hline \multirow[t]{2}{*}{ NSR } & $x_{1}+x_{2}$ & $\begin{array}{l}24.26 \\
(26.61)\end{array}$ & $\begin{array}{l}25.68 \\
(26.33)\end{array}$ & $\begin{array}{l}19.00 \\
(27.41)\end{array}$ & $\begin{array}{l}22.94 \\
(22.51)\end{array}$ & $\begin{array}{l}23.43 \\
(33.97)\end{array}$ \\
\hline & $x_{1}+x_{2}>0$ & $72.3 \%$ & $76.6 \%$ & $56.7 \%$ & $78.1 \%$ & $50 \%$ \\
\hline \multirow[t]{2}{*}{ NSR_sure } & $x_{1}$ & $\begin{array}{l}16.00 \\
(19.21)\end{array}$ & $\begin{array}{l}17.42 \\
(18.52)\end{array}$ & $\begin{array}{l}10.73 \\
(21.09)\end{array}$ & $\begin{array}{l}16.65 \\
(18.66)\end{array}$ & $\begin{array}{l}12.00 \\
(16.88)\end{array}$ \\
\hline & $x_{1}>0$ & $65.3 \%$ & $70.3 \%$ & $46.7 \%$ & $68.8 \%$ & $46.4 \%$ \\
\hline \multirow[t]{2}{*}{ NSR_risky } & $x_{2}$ & $\begin{array}{l}8.26 \\
(16.2)\end{array}$ & $\begin{array}{l}8.25 \\
(15.33)\end{array}$ & $\begin{array}{l}8.27 \\
(19.37)\end{array}$ & $\begin{array}{l}6.29 \\
(12.16)\end{array}$ & $\begin{array}{l}11.43 \\
(24.6)\end{array}$ \\
\hline & $x_{2}>0$ & $39.7 \%$ & $40.5 \%$ & $36.7 \%$ & $39.6 \%$ & $28.6 \%$ \\
\hline
\end{tabular}

We note that lottery choices over own and other's payoff are significantly correlated as reported in Table 4. However, $54 \%$ of the participants switched between the two choices and 106 out of 247 chose the lottery for the other player that they believed to be the mode choice. ${ }^{11}$

The summary statistics for decisions in the dictator games in Part 2 are presented in Table 5. We report average giving across all players as well as decisions separated by risk types. Compared to the standard dictator game NR, we find that average giving decreases from 22.5 to 19.6 tokens in OR, i.e. when the payoff to the recipient is risky ( $p<0.01$, Wilcoxon signed-rank test on equality of distributions). Even though significant, the effect size is smaller than in Brock et al. (2013) which hints at the importance of having closed the 'moral wiggle room' as in Krawczyk and LeLec (2010) and in line with the discussion in Krawczyk and LeLec (2016) and Brock et al. (2016). Riskiness of own payoff leads to a significantly larger decline to 15.1 tokens (SR<NR, $p<0.01$; SR<OR, $p<0.01$ ). Reintroducing a safe transfer option in NOR (24.0 tokens) and NSR (24.3 tokens) stabilizes total giving at the level of the standard dictator game, albeit both the safe and the risky transfer options are used. ${ }^{12}$ It is noteworthy that the percentages of players giving positive amounts are very similar across treatments (varying between 71.6 and $75.2 \%$ ), except for SR (56.0\%). Thus, the decision to give or not to give seems largely unaffected by the introduction of risk for all types of players as long as giving does not introduce risk on own income. In contrast, the share of subjects who give a positive amount decreases substantially when giving necessarily generates risk to own payoff. ${ }^{13}$ Consistent with previous literature, these treatment differences show that ex ante preferences based on comparisons of expected values alone cannot explain the data. Conversely, the decline of giving from NR to both OR and SR is consistent with ex post comparisons, while ex post payoff inequality à la Fehr and Schmidt (1999) as modeled in Brock et al. (2013) cannot explain the significant use of the risky transfer option in NOR which may trigger disadvantageous inequality.

As we are mainly interested in clarifying how risk preferences affect prosocial decisions, we now separate treatment effects depending on risk attitudes. Interestingly, risk aversion generally correlates with prosocial behavior in the standard

\footnotetext{
${ }^{11} L_{\text {belief }}$ does not have explanatory power beyond the decisions actually taken for others $\left(L_{\text {other }}\right)$ or for oneself $\left(L_{o w n}\right)$ and therefore is not used in the analysis reported below.

12 Interestingly, the average treatment effects are quite accurately anticipated by the receivers in the risk treatments as reported in Table 6 . Furthermore, recipients appear to take the risk into account when evaluating the fairness of a dictator's allocation decision: for example, recipients view the significantly reduced giving in SR relative to NR as only marginally less fair.

${ }^{13}$ Using bootstrapped t-tests that take the cardinal information in the data into account, we arrive at the same conclusions on the significance of treatment differences, except for the change from NR to OR, which is no longer shown to be significant.
} 
Table 6

Summary (mean (std.)) of expectations, giving, and fairness judgments (scale: 1 (very fair) - 5 (unfair)) of receivers in Part 2.

\begin{tabular}{|c|c|c|c|}
\hline Treatment & $\begin{array}{l}\text { Expectation } \\
\text { (by receiver) }\end{array}$ & $\begin{array}{l}\text { Giving } \\
\text { (by proposer) }\end{array}$ & $\begin{array}{l}\text { Fairness judgment } \\
\text { (by receiver) }\end{array}$ \\
\hline NR & $\begin{array}{l}17.72 \\
(20.36)\end{array}$ & $\begin{array}{l}22.46 \\
(21.32)\end{array}$ & $\begin{array}{l}3.23 \\
(1.77)\end{array}$ \\
\hline OR & $\begin{array}{l}17.25 \\
(22)\end{array}$ & $\begin{array}{l}19.60 \\
(22.13)\end{array}$ & $\begin{array}{l}3.33 \\
(1.66)\end{array}$ \\
\hline SR & $\begin{array}{l}14.79 \\
(23.78)\end{array}$ & $\begin{array}{l}15.11 \\
(22.89)\end{array}$ & $\begin{array}{l}3.55 \\
(1.57)\end{array}$ \\
\hline NOR & $\begin{array}{l}22.14 \\
(27.11)\end{array}$ & $\begin{array}{l}24.04 \\
(25.67)\end{array}$ & $\begin{array}{l}3.52 \\
(1.58)\end{array}$ \\
\hline NOR_sure & $\begin{array}{l}14.15 \\
(19.87)\end{array}$ & $\begin{array}{l}13.84 \\
(17.72)\end{array}$ & \\
\hline NOR_risky & $\begin{array}{l}7.99 \\
(13.09)\end{array}$ & $\begin{array}{l}10.20 \\
(15.36)\end{array}$ & \\
\hline NSR & $\begin{array}{l}23.8 \\
(29.46)\end{array}$ & $\begin{array}{l}24.26 \\
(26.61)\end{array}$ & $\begin{array}{l}3.48 \\
(1.63)\end{array}$ \\
\hline NSR_sure & $\begin{array}{l}15.82 \\
(19.14)\end{array}$ & $\begin{array}{l}16 \\
(19.21)\end{array}$ & \\
\hline NSR_risky & $\begin{array}{l}7.99 \\
(16.98)\end{array}$ & $\begin{array}{l}8.26 \\
(16.20)\end{array}$ & \\
\hline
\end{tabular}

dictator game: RAown players give 24.8 tokens while NRAown players only give 13.8 ( $p<0.01$, MW-U test). That is, players who are risk-averse with respect to their own payoff give more to other players in the absence of risk. A desire to reduce differences of own payoffs across different states of the world is therefore correlated with a desire to reduce differences between payoffs of different players. This finding is consistent with risk aversion being correlated with inequality aversion, in line with findings on behavior under a veil of ignorance (e.g., Schildberg-Hörisch, 2010; Frignani and Ponti, 2012).

We identify substantial heterogeneities in treatment effects. The average treatment differences are particularly driven by risk-averse players: giving of RAown proposers declines from NR to OR and more strongly from NR to SR (NR>OR, NR>SR, $\mathrm{OR}>\mathrm{SR}$, all $p<0.01$, Wilcoxon). In other words, not only risk for oneself, but also risk to the other player results in reduced giving by risk-averse players. This finding relates to a 'crowding out' effect of social preferences if those are in conflict with risk preferences as proposed by Güth et al. (2008). When a safe giving option is reintroduced in NOR and NSR, total giving stabilizes for risk-averse types (RAown and RAother). Again in line with our hypotheses on the impact of risk aversion, risk-averse players in these treatments particularly use the safe giving option $\left(x_{1}>x_{2}, p<0.01\right.$, Wilcoxon).

It is intuitive that non-risk-averse players (NRAown) are not very responsive to the introduction of risks in OR and SR. NRAown players also use both the risky and safe giving channels in NOR and NSR to a similar extent. Importantly, however, giving by NRAother proposers in OR is substantially smaller than in NR (13.39 vs. 19.29 tokens, $p<0.1$, Wilcoxon). ${ }^{14}$ In contrast, giving by RAother proposers only decreases by a small (insignificant) amount. In line with this observation, the level of giving differs between RAother and NRAother types only in OR and for the sure channel in NOR, i.e. NOR_sure. ${ }^{15}$ Risk aversion w.r.t. the other player's payoff thus upholds giving when the other player's payoff becomes risky. This finding is consistent with the qualitative predictions based on comparison of certainty equivalents as suggested by Brock et al. (2016) which appear to dominate the price of giving effect suggested by Krawczyk and LeLec (2016).

The non-parametric results already indicate that risk attitudes (as measured by our task) are important drivers of prosocial actions under risk. In order to provide further evidence on how changes in giving from NR to OR and NR to SR are driven by risk attitudes, we rely on linear regressions which are reported in Table 7. These allow us to additionally consider the role that social information about the recipients' risk attitudes plays for giving decisions. We use OLS estimations with robust standard errors to explain differences in giving between OR and NR (GivingOR-GivingNR) in models (1)-(5). Our covariates of interest are risk preferences over others' payoff (RAother) and the actual risk attitudes of the partner (RApartner) in the information treatment. Regression (6) explains the difference in giving in SR vs. NR (GivingSR-GivingNR) by the proposers' own risk attitudes (RAown).

The negative and significant constant in column (1) and (2) is consistent with the non-parametric result that NRAother participants significantly reduce giving from NR to OR. This effect is no longer visible in (3), indicating that NRAother loses its impact when proposers additionally get information about the receiver's actual choice. When social information is given (3-5), the actual risk attitude of the matched partner (RApartner) has more explanatory power: again, those matched with a non-risk-averse partner reduce giving significantly (see column (5)). Importantly, and in line with the nonparametric results, dictators who believe the other player to be risk-averse (column (2)), or know to be matched with a risk-averse partner (column (5)) show a much smaller reduction of giving than than those giving to a non-risk-averse recipient, even

\footnotetext{
14 The limited significance may be partly due to the smaller number of NRAother players.

15 Bootstrapped $t$-tests again show very similar significance levels in differences between types and between treatments as identified by the nonparametric tests. The difference between NR and OR is not significant for RAother and the level of giving in NOR_sure is not significantly different comparing RAother and NRAother.
} 
Table 7

Linear regressions of differences in giving between NR and OR (1-5) and NR and SR (6).

\begin{tabular}{|c|c|c|c|c|c|c|}
\hline & (1) & (2) & $(3)$ & $(4)$ & $(5)$ & (6) \\
\hline Info-treatment & All & NoInfo & Info & Info & Info & All \\
\hline Dep.Var. & OR-NR & OR-NR & OR-NR & OR-NR & OR-NR & SR-NR \\
\hline RApartner & & & & $\begin{array}{l}6.56 \\
(1.42)\end{array}$ & $\begin{array}{l}6.46 \\
(1.47)\end{array}$ & \\
\hline RAother & $\begin{array}{l}3.10 \\
(0.80)\end{array}$ & $\begin{array}{l}7.83 \\
(1.34)\end{array}$ & $\begin{array}{l}-1.63 \\
(-0.34)\end{array}$ & $\begin{array}{l}-1.85 \\
(-0.40)\end{array}$ & & \\
\hline RAown & & & & & & $\begin{array}{l}-10.74^{*} \\
(-1.76)\end{array}$ \\
\hline Constant & $\begin{array}{l}-5.89^{*} \\
(-1.84)\end{array}$ & $\begin{array}{l}-10.64^{* *} \\
(-2.04)\end{array}$ & $\begin{array}{l}-1.14 \\
(-0.34)\end{array}$ & $\begin{array}{l}-6.28 \\
(-1.24)\end{array}$ & $\begin{array}{l}-7.67^{* *} \\
(-2.48)\end{array}$ & $\begin{array}{l}1.10 \\
(0.19)\end{array}$ \\
\hline Observations & 124 & 61 & 63 & 62 & 70 & 141 \\
\hline$R$-squared & 0.00 & 0.03 & 0.00 & 0.01 & 0.01 & 0.04 \\
\hline
\end{tabular}

Note: Robust $t$-statistics in parentheses. ${ }^{* * *} p<0.01,{ }^{* *} p<0.05,{ }^{*} p<0.1$. In the no information treatment, 47 proposers are RAother while 14 are NRAother (column (2)). In the information treatment 49 proposers are RAother while 14 are NRAother (column (3)), 58 receivers are RAown and 12 are NRAown which correspond to RApartner and NRApartner (column (5)).

though in both cases, (2) and (5), the differences of 7.83 and 6.46 tokens are not statistically significant $(p=0.18$ and $p=0.15$, respectively). ${ }^{16}$ When social information is given, this seems to be taken into account by at least a fraction of subjects and to have a comparable effect as the empathetic preferences on behalf of the other person. When risk for the dictator's payoff is introduced, column (6) of Table 7 shows that this does not change behavior for non-risk-averse players, while significantly different behavior results for risk-averse dictators who reduce their giving.

\section{Conclusions}

The comparison of giving decisions across our treatments contributes several insights into the role that risk preferences play for prosocial behavior. Risk-averse and not risk-averse proposers give very different amounts in the baseline, indicating an important correlation between risk attitudes and prosocial preferences. When the payoff of the dictator himself becomes risky, those who are risk-averse reduce giving, while non-risk-averse dictators do not. When the payoff of the recipient is subject to risk, dictators who know or believe the recipient to be non-risk-averse reduce giving, while a much smaller reduction occurs when the recipient is or is believed to be risk-averse.

In other words, we do not find evidence that believed or actual risk aversion of the recipient leads the dictator to give less. Instead, giving declines in particular to recipients who are believed to be or actually are non-risk-averse. While the observations for risk in proposers' own payoff are in line with the expectation by Krawczyk and LeLec (2016) that agents may give less "simply because keeping the tokens is more efficient" (p. 837), the former finding leads us to question this reason as the sole explanation. Instead, the differential treatment effect for OR would be in line with the ideas formulated in Brock et al. (2016) that risk aversion of the recipient may lead to (relatively) higher giving if dictators desire to give a particular certainty equivalent to the recipient. However, an exclusive reliance on certainty equivalents as entering ex ante preferences falls short of explaining the decline in giving to non-risk-averse agents in OR compared to certainty. As such, behavior appears to be consistent with inequality aversion w.r.t. certainty equivalents in combination with other motives like efficiency concerns or aversion to disadvantageous inequity. Given our data, we might speculate about another interpretation for the latter observation: we find that risk-averse agents give more in a standard dictator game. If subjects anticipate this correlation of types, they may be led to believe that a non-risk-averse recipient would not give them much if the roles were switched. As such, the level of risk aversion of the other player may serve as a signal of kindness (Rabin, 1993), thereby resulting in reduced giving to non-risk-averse subjects.

Overall, the results indicate important heterogeneities in which players adjust prosocial behavior when giving is risky. The heterogeneous treatment effects we observe lead us to conclude that a type-based analysis is of major importance in this sort of situations. Our study provides evidence on the impact of different dimensions of risk aversion on prosocial behavior under risk, however risk preferences as measured in our study cannot serve as a sole explanation for the observed giving pattern. A further exploration of the interaction between risk aversion and prosocial behavior appears a fruitful avenue for further research.

\section{Appendix A. Supplementary data}

Supplementary data associated with this article can be found, in the online version, at http://dx.doi.org/10.1016/ j.jebo.2017.07.017.

${ }^{16}$ RAown and NRAown have no predictive power to explain the difference between OR and NR, therefore the results are left out in Table 7. 


\section{References}

Agranov, M., Bisin, A., Schotter, A., 2014. An experimental study of the impact of competition for other people's money: the portfolio manager market? Exp. Econ. 17 (4), 564-585.

Bolton, G.E., Brandts, J., Ockenfels, A., 2005. Fair procedures: evidence from games involving lotteries. Econ. J. 115, 1054-1076.

Brock, J.M., Lange, A., Ozbay, E.Y., 2013. Dictating the risk - experimental evidence on giving in risky environments? Am. Econ. Rev. 103 (1), $415-437$.

Brock, J.M., Lange, A., Ozbay, E.Y., 2016. Dictating the risk: experimental evidence on giving in risky environments: reply? Am. Econ. Rev. 106 (3), $840-842$.

Chakravarty, S., Harrison, G.W., Haruvy, E.E., Rutstroem, E.E., 2011. Are you risk averse over other people's money? South. Econ. J. 77 (4), $901-913$.

Dana, J., Weber, R.A., Kuang, J.X., 2007. Exploiting moral wiggle room: experiments demonstrating an illusory preference for fairness? Econ. Theory 33 (1), $67-80$.

Dave, C., Eckel, C.C., Johnson, C.A., Rojas, C., 2010. Eliciting risk preferences: when is simple better? J. Risk Uncertain. 41 (3), $219-243$.

Eckel, C.C., Grossman, P.J., 2008. Forecasting risk attitudes: an experimental study using actual and forecast gamble choices? J. Econ. Behav. Organ. 68 (1), $1-17$.

Faro, D., Rottenstreich, Y., 2006. Affect, empathy, and regressive mispredictions of others' preferences under risk. Manag. Sci. 52 (4), 529-541.

Fehr, E., Schmidt, K.M., 1999. A theory of fairness, competition, and cooperation. Q. J. Econ. 114 (3), $817-868$

Fischbacher, U., 2007. z-tree: Zurich toolbox for ready-made economic experiments? Exp. Econ. 10 (2), 171-178

Frignani, N., Ponti, G., 2012. Risk versus social preferences under the veil of ignorance? Econ. Lett. 116 (2), $143-146$.

Fudenberg, D., Levine, D.K., 2012. Fairness, risk preferences and independence: Impossibility theorems. J. Econ. Behav. Organ. 81, 606-612.

Güth, W., Levati, M.V., Ploner, M., 2008. On the social dimension of time and risk preferences: an experimental study? Econ. Inquiry 46 (2), 261-272.

Krawczyk, M., LeLec, F., 2010. 'Give me a chance!' an experiment in social decision under risk. Exp. Econ. 13, 500-511.

Krawczyk, M., LeLec, F., 2016. Dictating the risk: experimental evidence on giving in risky environments: comment? Am. Econ. Rev. 106 (3), 836-839.

Pahlke, J., Strasser, S., Vieider, F.M., 2015. Responsibility effects in decision making under risk. J. Risk Uncertain. 51, $125-146$.

Rabin, M., 1993. Incorporating fairness into game theory and economics. Am. Econ. Rev., 1281-1302.

Rohde, I.M., Rohde, K.I., 2011. Risk attitudes in a social context. J. Risk Uncertain. 43, 205-225.

Saito, K., 2013. Social preferences under risk: equality of opportunity versus equality of outcome? Am. Econ. Rev. 103 (7), $3084-3101$.

Schildberg-Hörisch, H., 2010. Is the veil of ignorance only a concept about risk? an experiment. J. Public Econ. 94, 1062-1066. 